Journal of Advanced Research in Fluid Mechanics and Thermal Sciences

Journal homepage: www.akademiabaru.com/arfmts.html ISSN: 2289-7879

\title{
Triple Solutions and Stability Analysis of Mixed Convection Boundary Flow of Casson Nanofluid over an Exponentially Vertical Stretching/Shrinking Sheet
}

\author{
Sumera Dero ${ }^{1,2}$, Azizah Mohd Rohni ${ }^{1,{ }^{*}}$, Azizan Saaban $^{1}$ \\ 1 School of Quantitative Sciences, Universiti Utara Malaysia, 06010 Sintok, Kedah, Malaysia \\ University of Sindh, Jamshoro, Pakistan
}

ARTICLE INFO

\section{ABSTRACT}

\section{Article history:}

Received 29 March 2020

Received in revised form 21 April 2020

Accepted 21 April 2020

Available online 8 June 2020

\section{Keywords:}

Triple Solutions; Stability Analysis; Casson Nanofluid; Stretching/shrinking sheet

\begin{abstract}
In this paper, we studied the 2D steady laminar boundary layer flow and heat transfer of Casson based nanofluid over an exponentially vertical stretching and shrinking sheet using one phase model. The thermal radiation and heat source/sink parameters are incorporated in the heat transfer equation and the slip parameters for the velocity and temperature are considered in the boundary conditions. The similarity variables have been used to convert the governing equations as a system of partial differential equations to the ordinary differential equations. The transformed equations are then solved by applying shooting technique, shootlib in Maple software. The numerical solutions for the governing equations indicate that the triple solutions arise when high suction is imposed for both stretching/shrinking sheet at certain ranges of the pertinent parameters. To examine the stability of the solutions, stability analyses is done by using BVP4C in Matlab software. The first solution is found to be a stable solution and physical realizable while the remaining solutions are not stable. The inclusion of three different nanoparticles shows that Copper - Casson nanofluid has the highest heat transfer rate compared to Aluminum-Casson and Graphite Oxide-

Casson nanofluid.
\end{abstract}

Copyright $\odot 2020$ PENERBIT AKADEMIA BARU - All rights reserved

\section{Introduction}

The boundary layer fluid flow and the heat transfer characteristics through different surfaces have achieved great attention of the researchers due to numerous applications in industrial and engineering fields such as metal spinning, extrusion of the plastic sheets, food stuff wrapping, glassfiber production, artificial fibers, petroleum manufacturing goods, drawing of plastic films, paper production and hot rolling etc. Originally, Sakiadis [1] defined the concept of the boundary layer

\footnotetext{
* Corresponding author.

E-mail address: azizahrohni@yahoo.com (Azizah Mohd Rohni)
} 
theory at the uniformly moving surface. Later, Crane [2] worked on the linear stretching surface problems. Afterward the idea given by Crane was extended by many researchers in view of different types of stretching surfaces flow problems [3-5]. It was in 1999 when Magyari and Keller [6] started to examine the fluid flow on the exponential stretching sheet and then the study of shrinking sheet was pioneered by Miklavčič and Wang [7] by considering viscous fluid flow problems with suction effect. Later on, many researchers have used stretching/shrinking sheet in the study of the boundary layer fluid flow and the heat transfer problems [8-11].

The heat transfer has been playing a key role in the many industrial fields where cooling and heating processes are involved. The efficiency of heat transfer might be enhanced by rising thermal conductivity of common working fluids Kwak and Chongyoup [12]. Generally, heat transfer through Newtonian/non-Newtonian fluids possess low thermal transfers compared to thermal transfers of the solids. Therefore, the thermal transfers of the fluids may be increased by suspension of the smaller solid material particles to the fluids. Feasibility of suspension of the small size of the particles of nearly size micrometers or millimeters were examined by many researchers and the major advantages were pointed out by Khanafer et al., [13]. The current development in the nanotechnology have emphasized the researchers to study the future generation modern heat transfer fluids which are named as nanofluids. Choi and Jeffrey [14] were the first to introduce such type of the modern class of fluid. The word nanofluid alludes to those sorts of fluids which are made up of common fluids (Newtonian/non-Newtonian) due to suspensions of the nano size solid particles in it which profoundly increase the thermal properties of common fluids. To understand the flow and the heat transfer phenomena in nanofluid from mathematical perspective, two well-known models that are the Buongiorno [15] and the Tiwari and Manab [16] models are often used by researchers. The model proposed by Buongiorno is a two phase model in which the Brownian motion and the thermophoresis play a significant role in enhancement of the thermal properties of nanofluids. On the other hand, Tiwari-Das Model is a one phase model, in which volumetric fraction of solid nanoparticles possess an importance for enhancing thermal properties of nanofluid. Recent study related to nanofluid has been done by Che Sidik et al., [17] and the review on the application of nanofluid can be found in Khattak et al., [18].

Meanwhile, Casson fluid is a type of non-Newtonian fluid and the model of the Casson fluid was first presented by Casson in 1959. This is one of the rheological model that deals the flow of many fluids including chocolate, blood, stuffs, soup, slurries, jelly, artificial fibers. Casson fluid model reveals a yield stress. Actually, this fluid acts as a solid in case of shear stress is lesser than the yield stress. So, it begins to deform as shear stress come to be greater than yield stress. Some current study regarding to Casson fluid are found in [19-21].

In this study, we consider a non-Newtonian nanofluid where the base fluid is Casson fluid. Three different nanoparticles are considered: Copper ( $\mathrm{Cu}$ ), Aluminum (Al) and Graphite Oxide (GO). The main objective of this study is to find the multiple similarity solutions and stability analysis for the flow over exponentially vertical stretching/shrinking sheet with velocity and temperature slip effects. The study of multiplicity of solutions is important and has successfully conducted by many authors [22-26]. However, to our present knowledge, the study of multiple solutions of Casson nanofluid over an exponentially vertical stretching/shrinking sheet with the consideration of thermal radiation, heat source/sink, and slip parameters has not been performed before. It is hoped that the present study will help the researchers/practitioners to understand the behavior of the fluid. 


\section{Mathematical Formulation}

We have considered the incompressible two-dimensional steady boundary flow and the heat transfer of $\mathrm{Cu}, \mathrm{Al}$ and $\mathrm{GO}$-Casson based nanofluid along the exponentially vertical stretching and shrinking sheet using one phase model that is presented in Figure 1.

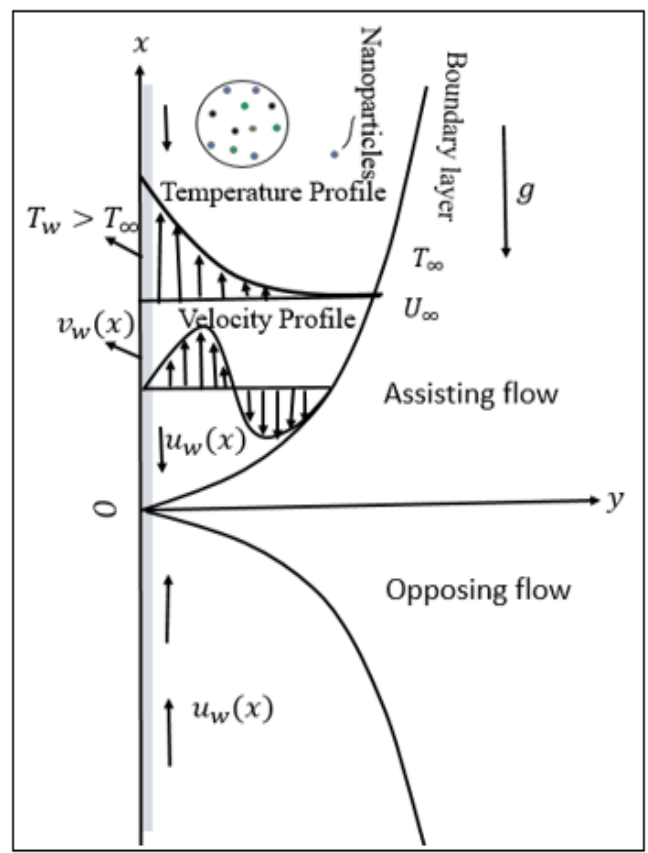

Fig. 1. Physical model of flow

It is assumed that the rheological equation of state to isotropic and the incompressible Casson fluid flow is written as in Mustafa and Junaid [27]:

$\tau_{i j}=\left\{\begin{array}{c}\left(\mu_{B}+\left(\frac{P_{y}}{\sqrt{2 \pi}}\right)\right) 2 e_{i j}, \pi>\pi_{C} \\ \left(\mu_{B}+\left(\frac{P_{y}}{\sqrt{2 \pi_{c}}}\right)\right) 2 e_{i j}, \pi<\pi_{c}\end{array}\right.$

where $\mu_{B}$ is plastic dynamics viscosity relative to non-Newtonian fluid, $P_{y}$ denotes fluid yield stress, $\pi$ denotes product of components of rate of deformation to itself, where $\pi=e_{i j} e_{i j}$ is $(i, j)$-th component of rate of deformation whereas turning point of $\pi$ is denoted by $\pi_{c}$. The sheet is exponentially stretched with $x$ axis and normal to the $y$ axis. Furthermore, the system of the governing equations of present analysis are as follows:

$\frac{\partial u}{\partial x}+\frac{\partial v}{\partial y}=0$

$u \frac{\partial u}{\partial x}+v \frac{\partial u}{\partial y}=\frac{\mu_{n f}}{\rho_{n f}}\left[\left(1+\frac{1}{\beta^{*}}\right) \frac{\partial^{2} u}{\partial y^{2}}+g(\rho \beta)_{n f}\left(T-T_{\infty}\right)\right]$

$u \frac{\partial T}{\partial x}+v \frac{\partial T}{\partial y}=\frac{1}{\left(\rho C_{p}\right)_{n f}}\left[k_{n f}\left(1+\frac{16 T_{\infty}^{3} \sigma^{*}}{3 k_{n f} k_{f}^{*}}\right) \frac{\partial^{2} T}{\partial y^{2}}+Q\left(T-T_{\infty}\right)\right]$ 
subject to boundary conditions,

$v=v_{w} ; u=\lambda u_{w}(x)+A \frac{\partial u}{\partial y} ; \quad T=T_{w}+D \frac{\partial T}{\partial y} ; \quad$ at $\quad y=0$

$u \rightarrow 0 ; \quad T \rightarrow T_{\infty} ; \quad$ as $y \rightarrow \infty$

where, $u$ and $v$ represent the components related to velocity in $x$ and $y$ directions. The sheet is assumed vertically stretched with velocity $u_{w}=U_{w} e^{\frac{x}{L}}$, here $U_{w}$ is constant of ambient velocity whereas $L$ is reference length. The surface temperature of sheet is taken as $T_{w}=T_{\infty}+T_{0} e^{\frac{2 x}{L}}$ where $T_{0}$ is constants and $T_{\infty}$ is ambient fluid temperature. $\rho_{n f}=(1-\phi) \rho_{f}+\phi \rho_{s}$ is effective density, $(\rho \beta)_{n f}=(1-\phi)(\rho \beta)_{f}+\phi(\rho \beta)_{s}$ denotes the effective thermal expansion coefficient of the nanofluid, $\mu_{n f}=\frac{\mu_{f}}{(1-\phi)^{2.5}}$ is effective dynamic viscosity, $\left(\rho c_{p}\right)_{n f}=(1-\phi)\left(\rho c_{p}\right)_{f}+\phi\left(\rho c_{p}\right)_{s}$ is the effective heat capacitance, $\alpha_{n f}=\frac{k_{n f}}{\left(\rho c_{p}\right)_{n f}}$ is the thermal diffusivity of nanofluid and $k_{n f}=$ $\frac{\left(k_{s}+2 k_{f}\right)-2 \phi\left(k_{f}-k_{s}\right)}{\left(k_{s}+2 k_{f}\right)+\phi\left(k_{f}-k_{s}\right)} k_{f}$ is thermal conductivity of nanofluid. $\lambda$ stands for the stretching and shrinking parameter, $A$ and $D$ are velocity and thermal slip factors, respectively.

The following similarity transformations are used to obtain similarity solutions of the governing equations.

$\psi=\sqrt{2 \vartheta l U_{w}} e^{x} / 2 l f(\eta) ; \theta(\eta)=\frac{T-T_{\infty}}{T_{w}-T_{\infty}} ; \quad \eta=y \sqrt{\frac{U_{w}}{2 \vartheta l}} e^{x / 2 l}$

In form of the velocity components, the stream function $\psi$ will be written as

$u=\frac{\partial \psi}{\partial y}, v=-\frac{\partial \psi}{\partial x}$

with the transformations given in Eq. (6), system of the Eq. (3) and Eq. (4) is written as

$$
\begin{aligned}
& \left(1+\frac{1}{\beta}\right) f^{\prime \prime \prime}+(1-\phi)^{2.5}\left[\begin{array}{c}
\left.\left(1-\phi+\phi\left(\frac{\rho_{s}}{\rho_{f}}\right)\right)\left(f f^{\prime \prime}-2 f^{\prime 2}\right)\right\} \\
+2 \xi\left(1-\phi+\phi \frac{(\rho \beta)_{s}}{(\rho \beta)_{f}}\right) \theta
\end{array}\right]=0 \\
& \left(1+\frac{4 R}{3}\right) \theta^{\prime \prime}+\operatorname{Pr} \frac{k_{f}}{k_{n f}}\left\{\left(1-\phi+\phi \frac{\left(\rho c_{p}\right)_{s}}{\left(\rho c_{p}\right)_{f}}\right)\left(f \theta^{\prime}-4 f^{\prime} \theta\right)+2 \chi \theta\right\}=0
\end{aligned}
$$

subjected to boundary conditions

$f(0)=S ; f^{\prime}(0)=\lambda+\delta f^{\prime \prime}(0) ; \theta(0)=1+\delta_{T} \theta^{\prime}(0)$, $f^{\prime}(\eta) \rightarrow 0 ; \theta(\eta) \rightarrow 0 ; \quad$ as $\eta \rightarrow \infty$

Moreover, $\xi=\frac{G r}{R e_{x}{ }^{2}}$ is mixed convection parameter where $G r=\frac{L^{3} g \beta_{f} T_{0}}{\vartheta_{f}{ }^{2}}$ is Grashof number, $R e=$ $\frac{L U_{w}}{\vartheta_{f}}, R=\frac{4 T_{\infty}^{3} \sigma^{*}}{k_{n f} k_{f}^{*}}$ is radiation parameter, $\operatorname{Pr}=\frac{\vartheta_{f}\left(\rho c_{p}\right)_{f}}{k_{f}}$ is Prandtl number, $\chi=\frac{L Q}{\left(\rho c_{p}\right)_{f} u_{w}}$ is heat 
source/sink parameter and $S=-\sqrt{\frac{2 l}{\vartheta U_{w}}}$ is suction parameter, $\lambda$ is a stretching/shrinking parameter, $\delta=A \sqrt{\frac{U_{w}}{2 L \vartheta_{f}}} e^{\frac{x}{2 L}}$ is velocity slip and $\delta_{T}=D \sqrt{\frac{U_{w}}{2 L \vartheta}} e^{\frac{x}{2 L}}$ thermal slip parameters.

The skin-friction coefficient $\left(C_{f}\right)$ and local Nusselt number $\left(N_{u}\right)$ are written as

$C_{f}=\frac{\left[2 \tau_{w}\right]_{y=0}}{\rho U_{w}^{2} e^{2 x / l}}, \quad N_{u}=\frac{-x\left[\frac{\partial T}{\partial y}\right]_{y=0}}{\left(T_{w}-T_{\infty}\right)}$

where $\tau_{w}$ is shear stress of wall that is $\tau_{w}=\mu_{B}\left(1+\frac{1}{\beta}\right)\left(\frac{\partial u}{\partial y}\right)_{y=0}$.

Using Eq. (6) in above relations, we get

$C_{f}\left(\frac{R e}{2}\right)^{\frac{1}{2}}=\left(1+\frac{1}{\beta^{*}}\right) f^{\prime \prime}(0), \quad N_{u}(R e)^{-\frac{1}{2}}\left(\frac{2 l}{x}\right)^{\frac{1}{2}}=-\theta^{\prime}(0)$

where $R e=\frac{L U_{w}}{\vartheta_{f}}$ is local Reynolds number.

The boundary value problem (BVPs) consists on Eq. (7) and Eq. (8) subjected to initial and boundary conditions given in Eq. (9) are then solved by using shooting technique implemented by shootlib function in Maple software [28]. The thermo-physical properties of Casson base fluid and applied nano-particles are presented in the Table 1.

Table 1

Thermo physical properties of the Casson fluid and the nanoparticles [26]

\begin{tabular}{lllll}
\hline & $\rho\left(\mathrm{kgm}^{-3}\right)$ & $C_{p}\left(\mathrm{~kg}^{-1} \mathrm{k}^{-1}\right)$ & $k\left(\mathrm{Wm}^{-1} \mathrm{k}^{-1}\right)$ & $\beta \times 10^{-5}\left(\mathrm{k}^{-1}\right)$ \\
\hline $\mathrm{C}_{6} \mathrm{H}_{9} \mathrm{NaO}_{7}$ & 989 & 4175 & 0.6376 & 23 \\
$\mathrm{Al}$ & 2701 & 902 & 237 & 2.31 \\
Graphite oxide $(\mathrm{GO})$ & 1800 & 717 & 5000 & 28.4 \\
$\mathrm{Cu}$ & 8933 & 385 & 400 & 1.67 \\
\hline
\end{tabular}

\section{Stability Analysis}

To employ the stability analysis, Eq. (3) and Eq. (4) should be rewritten in unsteady case. Thus, we have

$$
\begin{aligned}
& \frac{\partial u}{\partial t}+u \frac{\partial u}{\partial x}+v \frac{\partial u}{\partial y}=\frac{1}{\rho_{n f}}\left[\mu_{n f}\left(1+\frac{1}{\beta^{*}}\right) \frac{\partial^{2} u}{\partial y^{2}}+g(\rho \beta)_{n f}\left(T-T_{\infty}\right)\right] \\
& \frac{\partial T}{\partial t}+u \frac{\partial T}{\partial x}+v \frac{\partial T}{\partial y}=\frac{1}{\left(\rho C_{p}\right)_{n f}}\left[k_{n f}\left(1+\frac{16 T_{\infty}^{3} \sigma^{*}}{3 k_{n f} k_{f}^{*}}\right) \frac{\partial^{2} T}{\partial y^{2}}+Q\left(T-T_{\infty}\right)\right]
\end{aligned}
$$

here $t$ is time. Now, a new dimensionless variable $\tau$ is introduced, then Eq. (6) can be written as follows 
$\psi=\sqrt{2 U_{w} \vartheta L} e^{\frac{x}{2 L}} f(\eta, \tau) ; \theta(\eta, \tau)=\frac{T-T_{\infty}}{T_{w}-T_{\infty}} ; \eta=y \sqrt{\frac{U_{w}}{2 L \vartheta}} e^{\frac{x}{2 L}}$ and $\tau=\frac{U_{w}}{2 l} e^{x / L t}$

where, $u=U_{w} e^{\frac{x}{L}} f^{\prime}(\eta, \tau), v=-\sqrt{\frac{U_{w} \vartheta_{f}}{2 L}} e^{\frac{x}{2 L}}\left[f(\eta, \tau)+\eta f^{\prime}(\eta, \tau)\right]$.

By applying Eq. (13) in Eq. (11) and Eq. (12), we obtained:

$$
\begin{aligned}
& \left(1+\frac{1}{\beta^{*}}\right) \frac{\partial^{3} f(\eta, \tau)}{\partial \eta^{3}}+(1-\phi)^{2.5}\left[( ( 1 - \phi ) + \phi ( \rho _ { s } / \rho _ { f } ) ) \left\{f(\eta, \tau) \frac{\partial^{2} f(\eta, \tau)}{\partial \eta^{2}}-2\left(\frac{\partial f(\eta, \tau)}{\partial \eta}\right)^{2}-\right.\right. \\
& \left.\left.2 \tau \frac{\partial^{2} f(\eta, \tau)}{\partial \eta \partial \tau} \frac{\partial f(\eta, \tau)}{\partial \eta}-\frac{\partial^{2} f(\eta, \tau)}{\partial \eta \partial \tau}\right\}+2 \xi\left(1-\phi+\phi \frac{(\rho \beta)_{s}}{(\rho \beta)_{f}}\right) \theta(\eta, \tau)\right]=0 \\
& \frac{1}{\operatorname{Pr}} \frac{k_{n f}}{k_{f}}\left(1+\frac{4 R}{3}\right) \frac{\partial^{2} \theta(\eta, \tau)}{\partial \eta^{2}}+\left(1-\phi+\phi \frac{\left(\rho c_{p}\right)_{s}}{\left(\rho c_{p}\right)_{f}}\right)\left[f(\eta, \tau) \frac{\partial \theta(\eta, \tau)}{\partial \eta}-4 \frac{\partial f(\eta, \tau)}{\partial \eta} \theta(\eta, \tau)-\right. \\
& \left.2 \tau f^{\prime}(\eta, \tau) \frac{\partial \theta(\eta, \tau)}{\partial \tau}-\frac{\partial \theta(\eta, \tau)}{\partial \tau}\right]-2 \chi \theta(\eta, \tau)=0
\end{aligned}
$$

the boundary conditions become

$f(0, \tau)=S ; \frac{\partial f(0, \tau)}{\partial \eta}=\lambda+\delta \frac{\partial^{2} f(0, \tau)}{\partial \eta^{2}} ; \quad \theta(0, \tau)=1+\delta_{T} \frac{\partial \theta(0, \tau)}{\partial \eta} ;$

$\frac{\partial f(\eta, \tau)}{\partial \eta} \rightarrow 0 ; \theta(\eta, \tau) \rightarrow 0 ; \quad$ as $\eta \rightarrow \infty$

In order to test the stability of solutions of $f(\eta)=f_{0}(\eta)$ and $\theta(\eta)=\theta_{0}(\eta)$, that satisfy boundary value problems Eq. (7)-(9) we have

$$
\begin{aligned}
& f(\eta, \tau)=f_{0}(\eta)+e^{-\varepsilon \tau} F(\eta, \tau) \\
& \theta(\eta, \tau)=\theta_{0}(\eta)+e^{-\varepsilon \tau} G(\eta, \tau)
\end{aligned}
$$

where both $F(\eta, \tau)$ and $G(\eta, \tau)$ are small relative to $f_{0}(\eta)$ and $\theta_{0}(\eta)$, respectively, $\varepsilon$ is the unknown eigenvalue that provides an infinite set of the eigenvalues $\varepsilon<\varepsilon_{1}<\varepsilon_{2}<\varepsilon_{3}$... The stability of solution depends upon sign of smallest eigenvalue $\varepsilon$. If value of $\varepsilon_{1}$ is positive that show the flow is a stable and there is the initial decay. Conversely, if value of $\varepsilon$ is negative that shows the flow is the unstable and illustrate an initial growth of disturbance. By substituting Eq. (17) in Eq. (14)-(16), we obtained

$$
\begin{aligned}
& \left(1+\frac{1}{\beta^{*}}\right) F_{0}^{\prime \prime \prime}+(1-\phi)^{2.5}\left[\left(1-\phi+\phi\left(\frac{\rho_{s}}{\rho_{f}}\right)\right)\left(f_{0} F_{0}^{\prime \prime}+F_{0} f_{0}^{\prime \prime}+2 \tau \varepsilon f_{0}^{\prime} F_{0}^{\prime}-4 f_{0}^{\prime} F_{0}^{\prime}+\varepsilon F_{0}^{\prime}\right)+\right. \\
& \left.2 \xi\left(1-\phi+\phi \frac{(\rho \beta)_{s}}{(\rho \beta)_{f}}\right) G\right]=0 \\
& \left(1+\frac{4 R}{3}\right) G_{0}^{\prime \prime}+\operatorname{Pr} \frac{k_{f}}{k_{n f}}\left[\left(1-\phi+\phi \frac{\left(\rho c_{p}\right)_{s}}{\left(\rho c_{p}\right)_{f}}\right)\left\{f_{0} G_{0}^{\prime}+F_{0} \theta_{0}^{\prime}+2 \tau \varepsilon f^{\prime}{ }_{0} G-4 f^{\prime}{ }_{0} G_{0}-4 F^{\prime} \theta_{0}+\varepsilon G_{0}\right\}-\right. \\
& \left.2 \chi G_{0}\right]=0
\end{aligned}
$$


To obtain the steady state solution and taking $\tau=0$,

$$
\begin{aligned}
& \left(1+\frac{1}{\beta^{*}}\right) F_{0}^{\prime \prime \prime}+(1-\phi)^{2.5}\left[\left(1-\phi+\phi\left(\frac{\rho_{s}}{\rho_{f}}\right)\right)\left(f_{0} F_{0}^{\prime \prime}+F_{0} f_{0}^{\prime \prime}-4 f_{0}^{\prime} F_{0}^{\prime}+\varepsilon F_{0}^{\prime}\right)+2 \xi(1-\phi+\right. \\
& \left.\left.\phi \frac{(\rho \beta)_{s}}{(\rho \beta)_{f}}\right) G\right]=0 \\
& \left(1+\frac{4 R}{3}\right) G_{0}^{\prime \prime}+\operatorname{Pr} \frac{k_{f}}{k_{n f}}\left[\left(1-\phi+\phi \frac{\left(\rho c_{p}\right)_{s}}{\left(\rho c_{p}\right)_{f}}\right)\left\{f_{0} G_{0}^{\prime}+F_{0} \theta_{0}^{\prime}-4 f_{0}^{\prime} G_{0}-4 F^{\prime} \theta_{0}+\varepsilon G_{0}\right\}-2 \chi G_{0}\right] \\
& \quad=0
\end{aligned}
$$

subjecting to boundary conditions,

$$
\begin{aligned}
& F_{0}(0)=0, \quad F_{0}^{\prime}(0)=\delta F_{0}^{\prime \prime}(0), \quad G_{0}(0)=\delta_{T} G_{0}^{\prime}(0), \\
& F_{0}^{\prime} \quad(\eta) \rightarrow 0, \quad G_{0}(\eta) \rightarrow 0, \quad \text { as } \eta \rightarrow \infty
\end{aligned}
$$

To obtain stability analysis of the solutions, Eq. (20) and Eq. (21) of linear eigenvalue problem along the boundary conditions in Eq. (22) have been solved by collocation method using bvcp4c solver functions in the Matlab software and obtained the smallest eigenvalue $\varepsilon$. To obtain smallest eigenvalues, there is a need to relax one of the boundary conditions in form of the initial condition as in Haris et al., [29]. In this problem, $F_{0}{ }^{\prime}(\eta) \rightarrow 0$ as $\eta \rightarrow \infty$ has been relaxed in the initial form as $F^{\prime \prime}{ }_{0}(0)=1$. It should be noted that the negative smallest eigenvalues point out initial development of the disturbance and the solution of the flow is unstable. On other hand, when the smallest related eigenvalue value is positive that shows the fluid flow is stable and physical realizable.

\section{Results and Discussion}

Numerical solutions for the governing Eq. (7) and Eq. (8) subject to boundary conditions given in Eq. (9) are found by shooting technique with the help of Maple software. Triple solutions are found at various initial guesses of missing values of the skin friction coefficient $f^{\prime \prime}(0)$ and local Nusselt number $-\theta^{\prime}(0)$ where the profiles satisfy the boundary conditions in Eq. (9) asymptotically.

To validate the accuracy of the present numerical results, we compare the present results with the results previously obtained by Jat and Gopi [30] in Table 2. As can be seen from Table 2, the current results show a good resemblance with those obtained by Jat and Gopi [30] and henceforth we believe that other obtained new solutions in our study are also correct.

\section{Table 2}

Comparative results of the first solution for skin friction coefficient $f^{\prime \prime}(0)$ and local Nusselt number $\theta^{\prime}(0)$ for different values of $\operatorname{Pr}$ at $\lambda=1, \beta^{*} \rightarrow \infty$

\begin{tabular}{llllll}
\multicolumn{7}{c}{ and $\phi=S=\xi=\chi=\delta=\delta_{T}=0$} \\
\hline \multicolumn{5}{c}{ Jat and Gopi [30] } & \multicolumn{3}{l}{ Present } \\
$\operatorname{Pr}$ & $R d$ & $f^{\prime \prime}(0)$ & $\theta^{\prime}(0)$ & $f^{\prime \prime}(0)$ & $\theta^{\prime}(0)$ \\
\hline 1 & 0 & -1.290377 & -0.977550 & -1.290377 & -0.977543 \\
1 & 0.5 & -1.290377 & -0.741726 & -1.290377 & -0.741738 \\
1 & 1 & -1.290377 & -0.632116 & -1.290377 & -0.632118 \\
\hline
\end{tabular}

Furthermore, numerical computations are performed to elaborate the skin friction, heat transfer, velocity and temperature profiles. The features are shown in Figure 2 to Figure 16. Figure 2 to Figure 
7 , indicate the effect of suction parameter $(S)$ on skin friction coefficient $f^{\prime \prime}(0)$ and the local Nusselt number $-\theta^{\prime}(0)$ of $C u, A l$ and $G O$-Casson base nanofluid due to variation of stretching and shrinking parameter $(\lambda)$, keeping values of other parameters fixed. It is seen that there exist three solutions for the case of $\lambda>\lambda_{c}$, whereas second and the third solutions join together at critical points $\lambda_{c}$, while first solution remains continuous to exist for both stretching and shrinking cases of $\lambda$. Moreover, Figure 2 to Figure 4 indicate the variations in skin friction coefficients $f^{\prime \prime}(0)$ regarding to stretching and shrinking parameter $(\lambda)$ for the different values of the suction parameter $S$. From these figures, it is observed that the magnitude of $f^{\prime \prime}(0)$ decrease in case of the stretching sheet $(\lambda>0)$ whereas opposite trend of the result is seen for shrinking sheet $(\lambda<0)$ in the first solution for selected three cases of the nanofluid due to increase in rate of suction. In second and third solutions, the magnitude of $f^{\prime \prime}(0)$ decreases in both solutions due to increment in $S$.

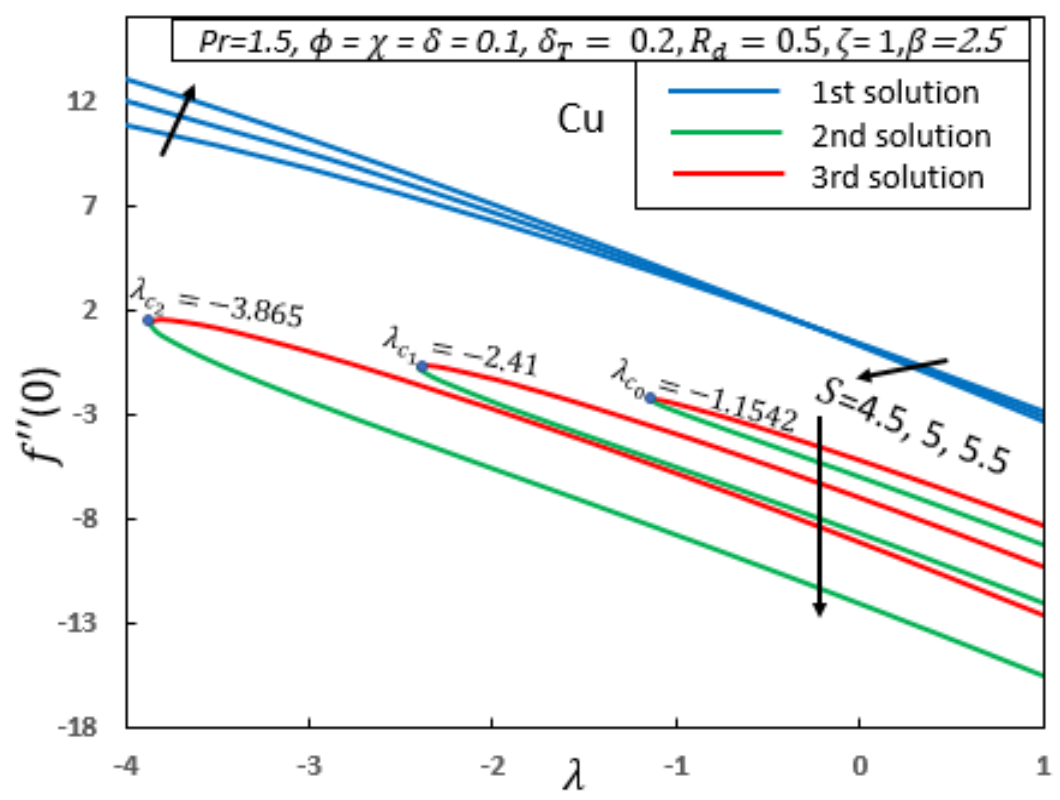

Fig. 2. Skin friction coefficient of $C u$ with variation of the $\lambda$ for different values of $S$

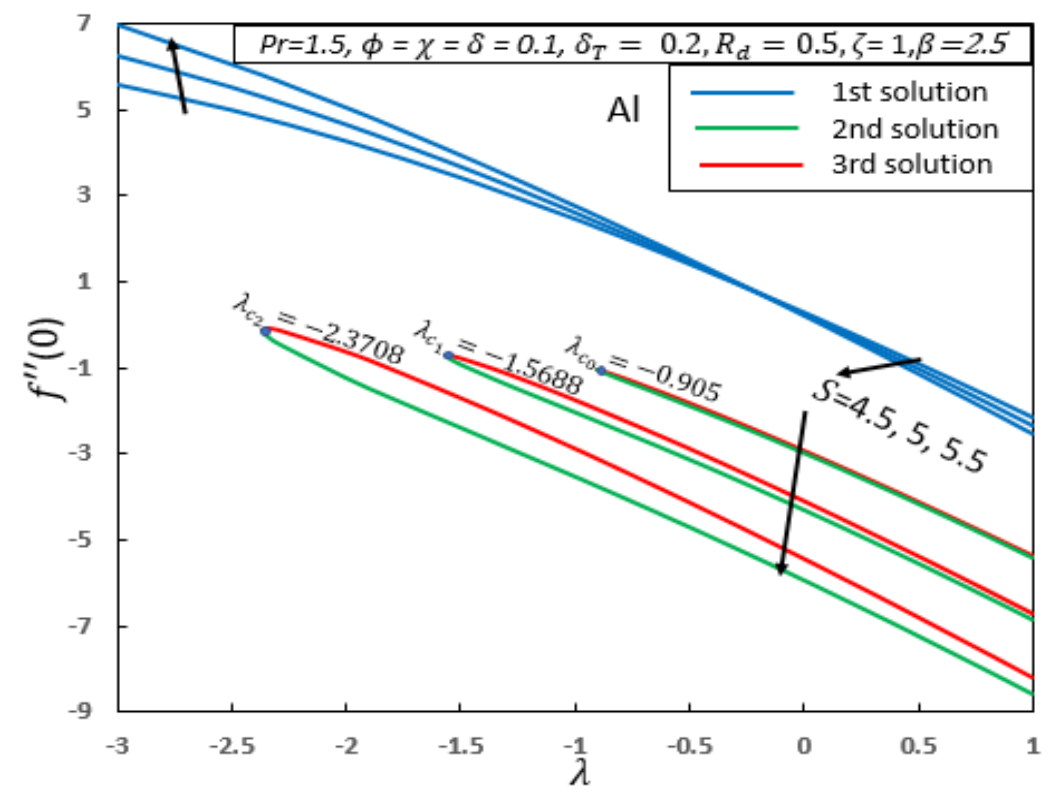

Fig. 3. Skin friction coefficient of $A l$ with variation of $\lambda$ for different values of $S$ 


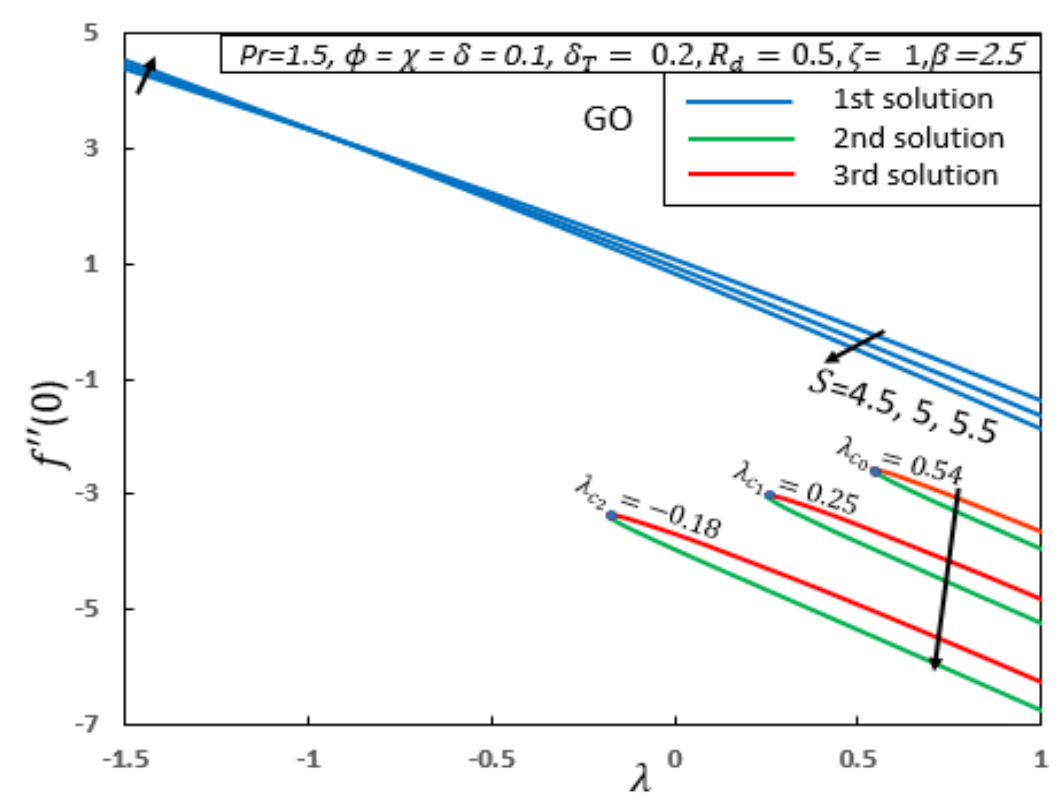

Fig. 4. Skin friction coefficient of $G O$ with variation of $\lambda$ for different values of $S$

Figure 5 to Figure 7 , illustrates variation of local Nusselt number $-\theta^{\prime}(0)$ with $\lambda$ for different values of the suction parameter $S$ for $\mathrm{Cu}, \mathrm{Al}$ and $\mathrm{GO}$-Casson base nanofluids. From these figures, it can be seen that an increase in the parameter $S$ causes the increament in magnitude of the $-\theta^{\prime}(0)$ in first solutions, whereas in second solutions a very small increments are observed at start but after a point magnitude of the Nusselt number decreases by enlarging range of the critical point. In third solution, the rate of the heat transfer increases throughout flow due to increment in $S$. It also can be seen from Figure 2 to Figure 7 that copper has the highest skin friction and heat transfer rate, followed by aluminium and graphite oxide.

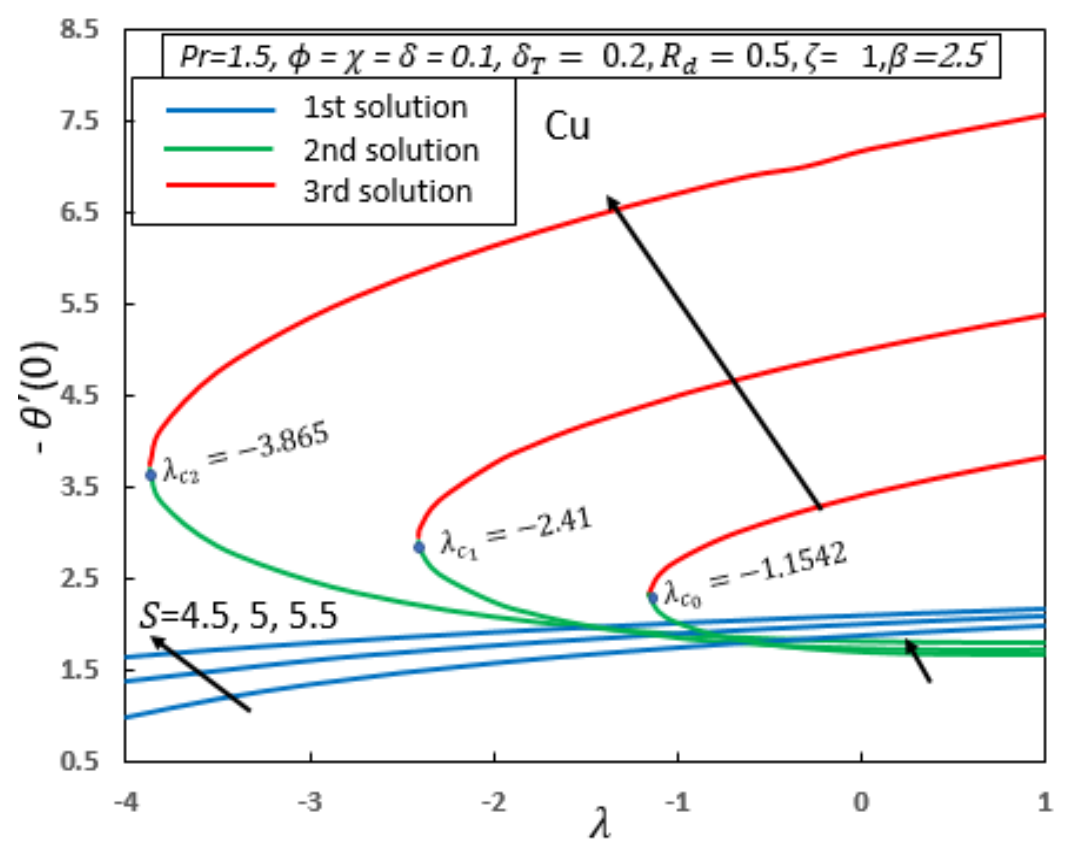

Fig. 5. Local Nusselt number of $C u$ with variation of $\lambda$ for different values of $S$ 


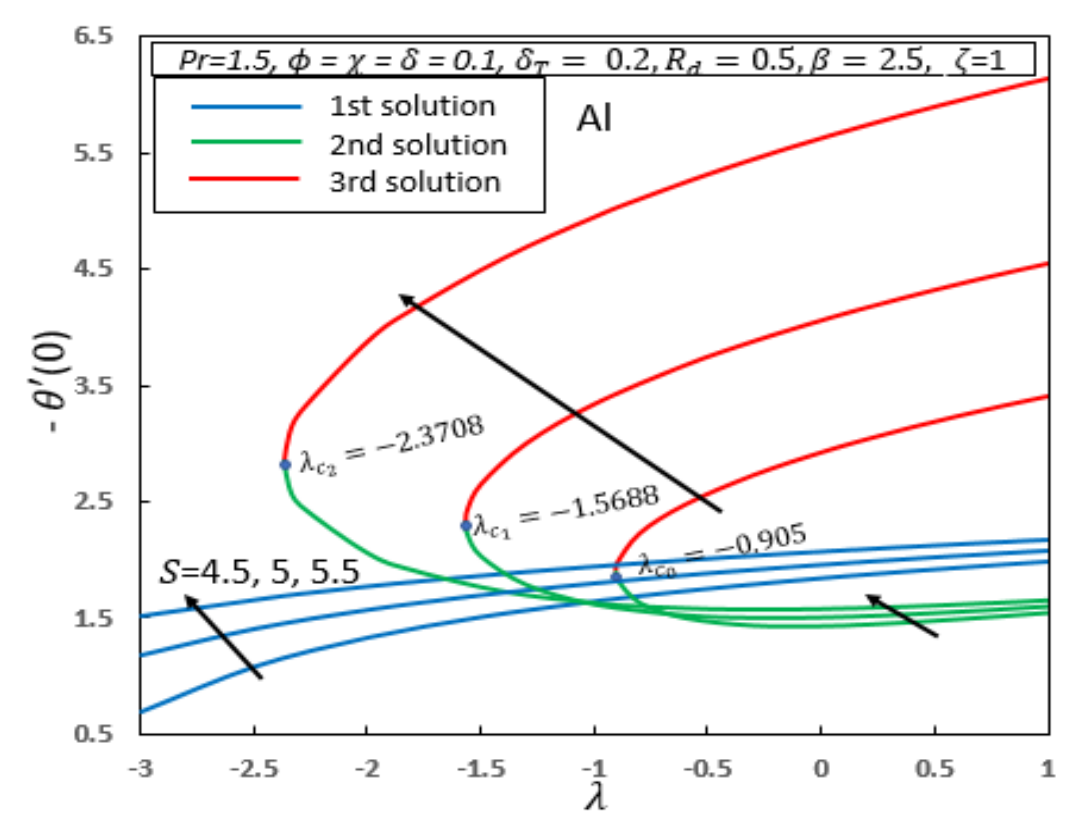

Fig. 6. Local Nusselt number of $A l$ with variation of $\lambda$ for different values of $S$

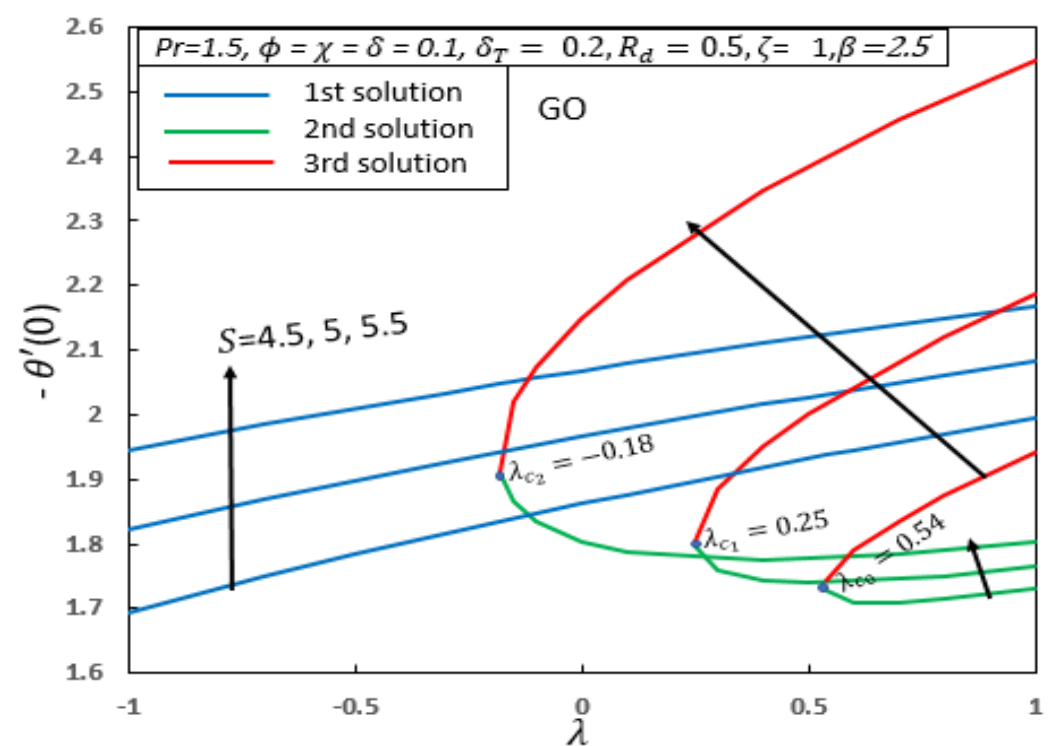

Fig. 7. Local Nusselt number of $G O$ with variation of $\lambda$ for different values of $S$

A comparative result of variations of the skin friction coefficient $f^{\prime \prime}(0)$ and the local Nusselt number $-\theta^{\prime}(0)$ along variation of volume fraction $\phi$ for the copper $(C u)$, Aluminum $(A l)$ and Graphite Oxide (GO) nanoparticles are presented in Figure 8 and Figure 9. Figure 8 shows that the suspension of Graphite Oxide nanoparticles in Casson fluid provides more drag force compared to copper and aluminum nanoparticles. Also, aluminum nanoparticle shows more drag force when compared to copper nanoparticle. In opposite, copper nanoparticles in Casson fluid provides more rate of the heat transfer enhancement compared to aluminum and graphite oxide nanoparticles that is shown in Figure 9. Figure 9 also show the more rate of the heat transfer enhancement of Aluminum nanoparticles compared to Graphite Oxide. 


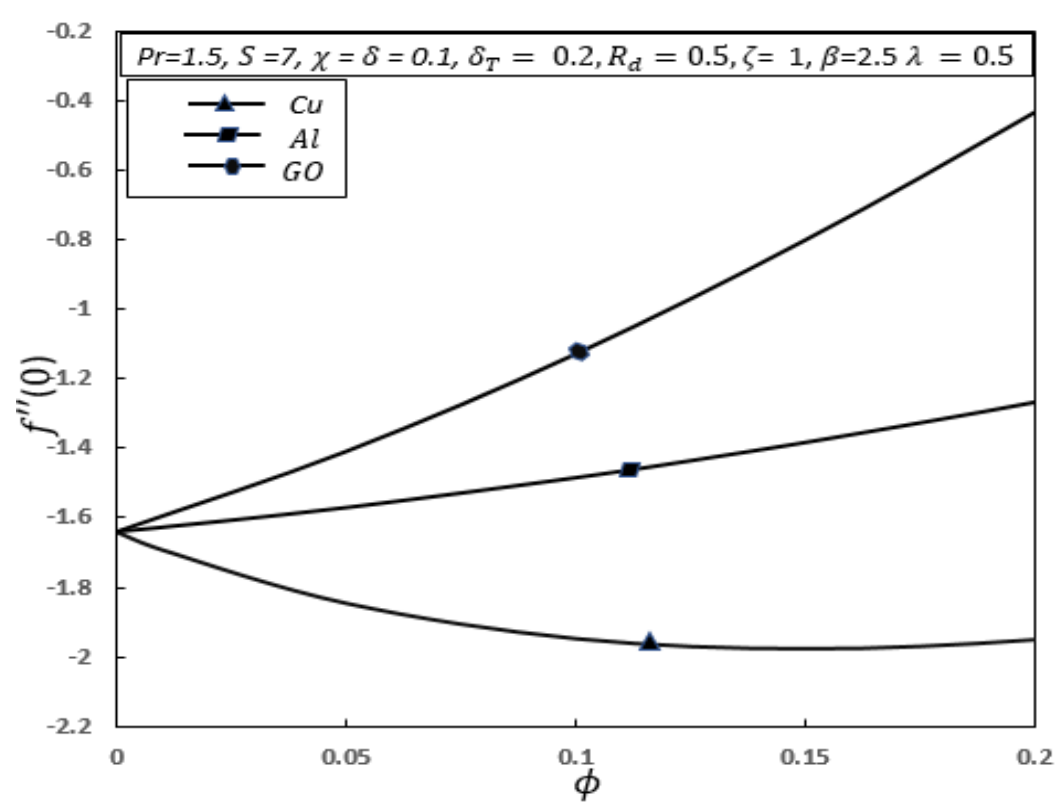

Fig. 8. The effects of the different nanoparticles on the skin friction coefficient $f^{\prime \prime}(0)$

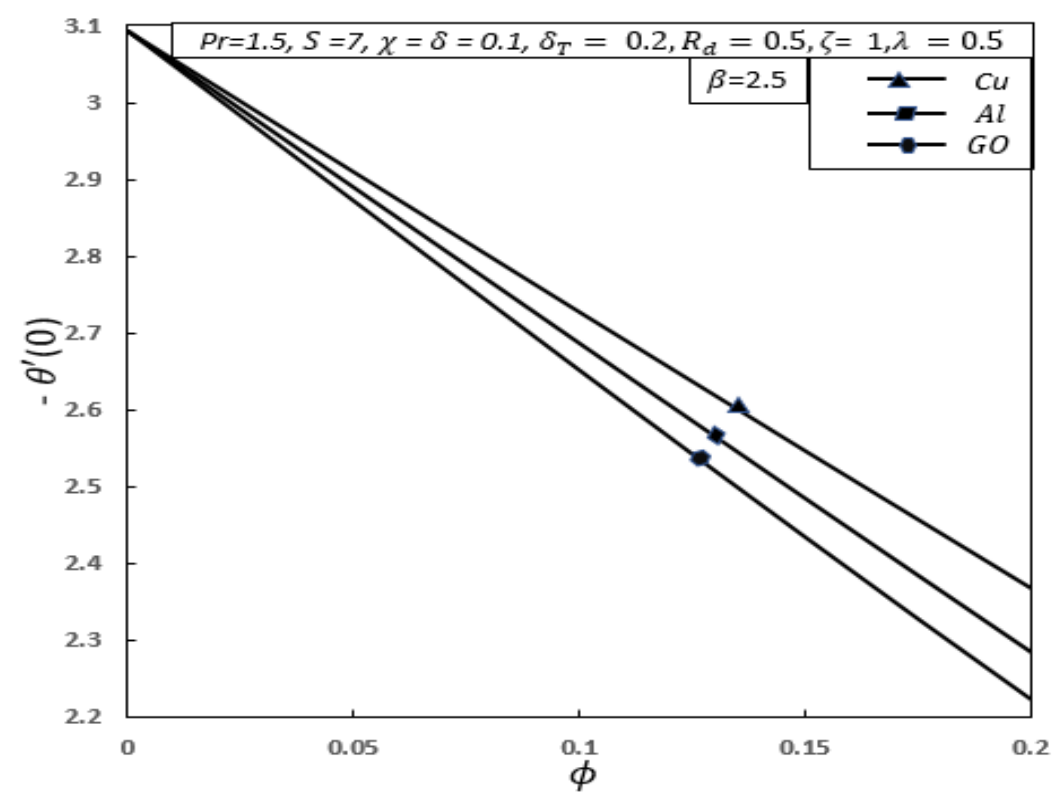

Fig. 9. The differentiation in influence between different nanoparticles on the local Nusselt number $-\theta^{\prime}(0)$

Figure 10 demonstrates that the increasing value of Casson parameter $\beta^{*}$ decreases the velocity profile $f^{\prime}(\eta)$ and also the boundary layer thickness of $C u$-Casson base nanofluid throughout the flow in first solution which is declared a feasible solution of the present study. Whereas in second and third solutions, velocity decreases initially but after a while it increases in both solutions. Actually, an increment in value of the parameter $\beta^{*}$ rises the effective dynamic viscosity. Therefore, increase in the resistance of the viscosity leads to declines the yield stress of fluid which drags to fluid flow to the stretching sheet. In result, velocity and thickness of its boundary layer decline due to increase in parameter $\beta^{*}$. 


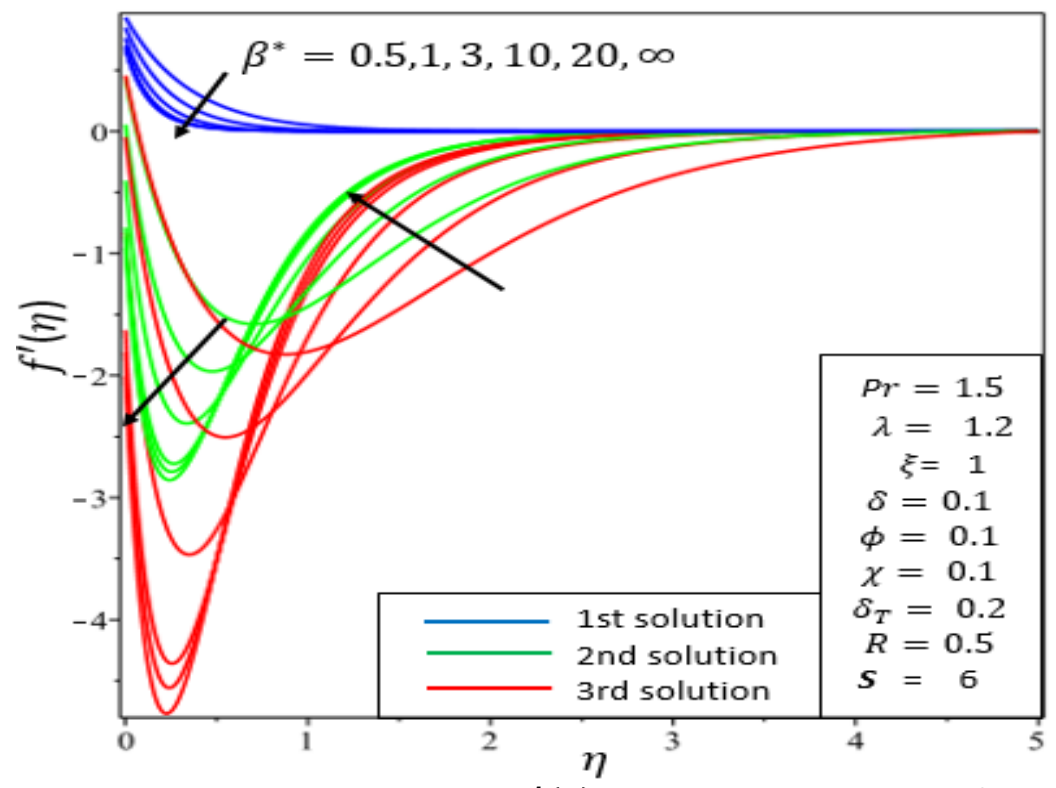

Fig. 10. The velocity profile $f^{\prime}(\eta)$ for different values of $\beta^{*}$

Figure 11 shows the increasing value of the velocity slip parameter $\delta$ decreases the velocity of Copper Casson based nanofluid in the first solution. Originally, increasing $\delta$ allows an extra fluid particle slipping on the sheet and the fluid flow decelerates close to the sheet. While in second and the third solutions any increment in values of parameter $\delta$ initially decreases the nanofluid velocity but after a point it begins to rise.

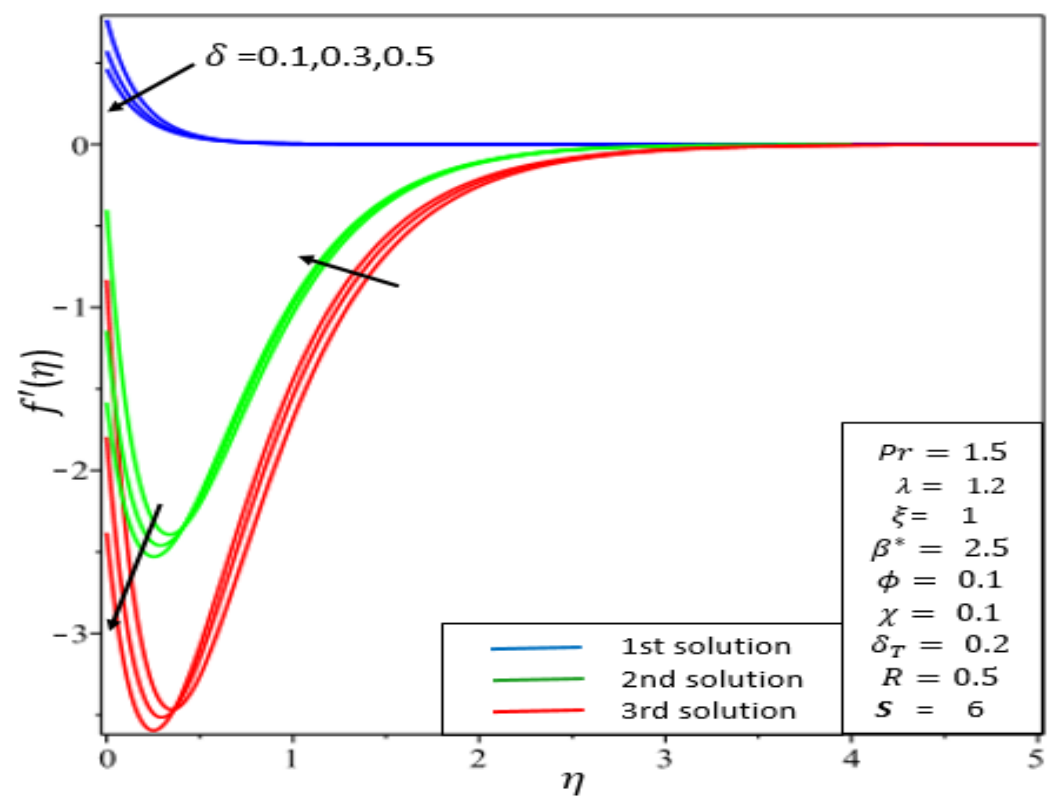

Fig. 11. The velocity profile $f^{\prime}(\eta)$ for different values of $\delta$

The effect of Copper nanoparticles volumetric fraction $\phi$ on the velocity profile $f^{\prime}(\eta)$ is depicted in Figure 12. From this figure, it is seen that the increasing quantity of Copper nanoparticles in Casson fluid decreases velocity profile and its boundary layer thickness in first solution. Fluctuation is observed in the second and third solutions where initially velocity profile decrease but after a point it starts increasing all over the flow. The effect of Copper nanoparticles volumetric fraction $(\phi)$ on temperature profile $\theta(\eta)$ is shown in the Figure 13. This figure demonstrates that the increasing quantity of the Copper nanoparticles increases the temperature profile of Casson fluid and its 
boundary layer thickness in first solution throughout the flow. In general, an increase in quantity of solid nanoparticles increases the thermal conductivity of the fluids that in result enhance the temperature profiles and its boundary layer thickness in general, while in second and third solutions the behavior is initially similar to the first solution but eventually changes in opposite way.

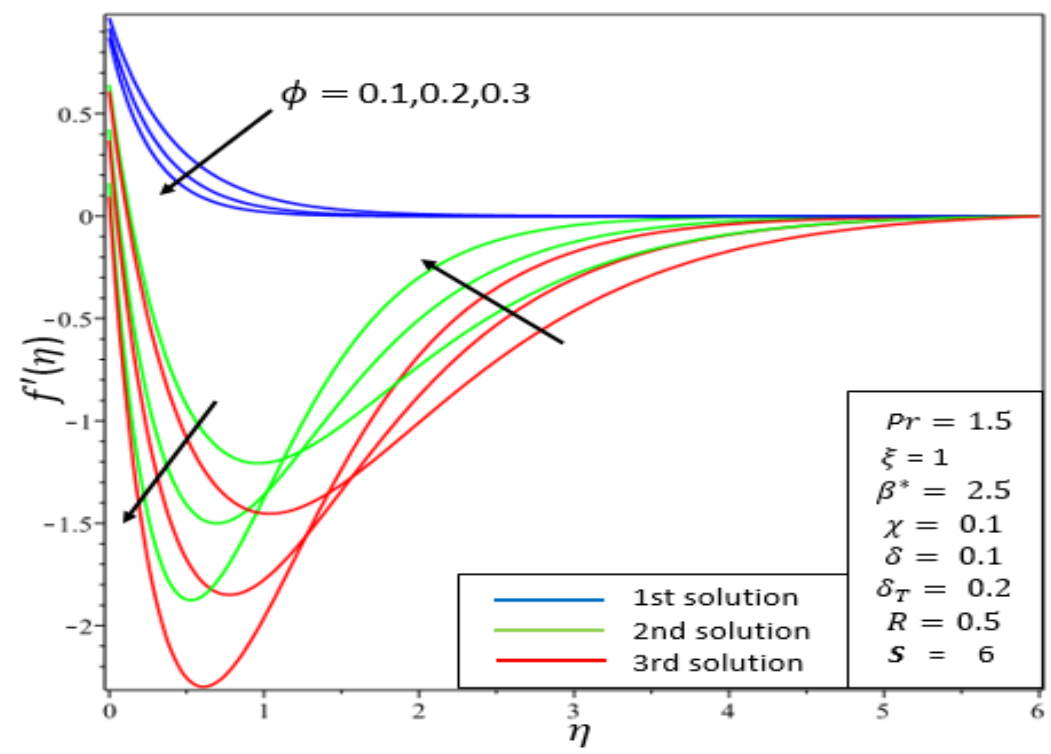

Fig. 12. The velocity profile $f^{\prime}(\eta)$ for different values of $\phi$

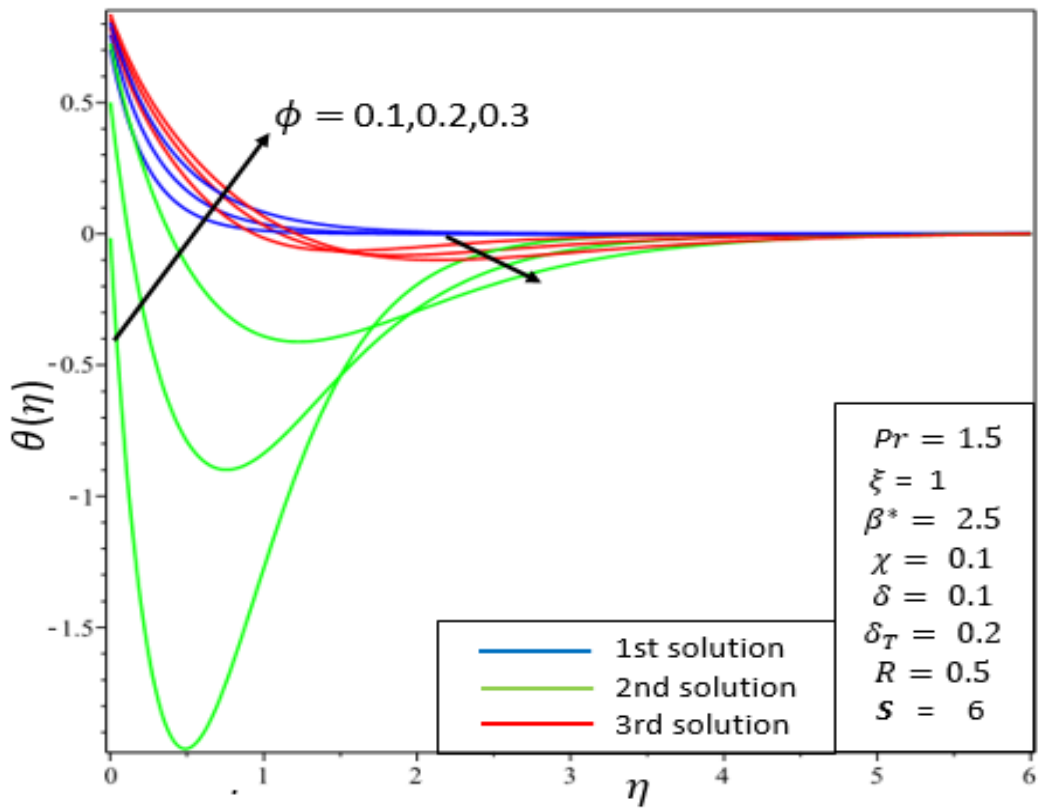

Fig. 13. The temperature profile $\theta(\eta)$ for different values of $\phi$

The effect of thermal radiation parameter $(R)$ on the temperature profile $\theta(\eta)$ is presented in Figure 14. It can be examined from this figure, an increase in the value of thermal radiation parameter $(R)$, the temperature profile and its boundary layer thickness are increasing in the first solution clearly. While in the second and third solution partially, at start it increase but after a point it decreases in both unstable solutions.

Figure 15 shows the effect of thermal slip parameter $\left(\delta_{T}\right)$ on the temperature profile $\theta(\eta)$. This figure implies that the temperature and its boundary layer thickness reduce due to increase in thermal slip parameter $\delta_{T}$ in all three solutions. Originally, because of rise in the parameter $\delta_{T}$, a 
small amount of the heat energy is transported to the nanofluids. Therefore, in result temperature of the nanofluid decrease.

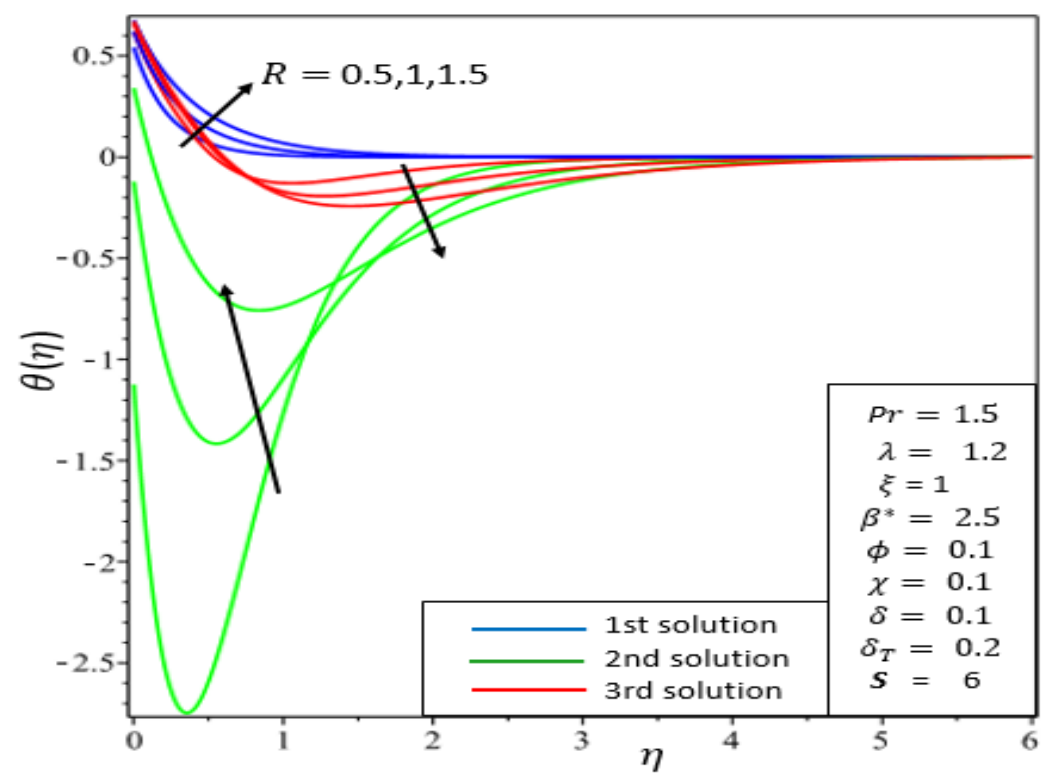

Fig. 14. The temperature profile $\theta(\eta)$ for different values of $R$

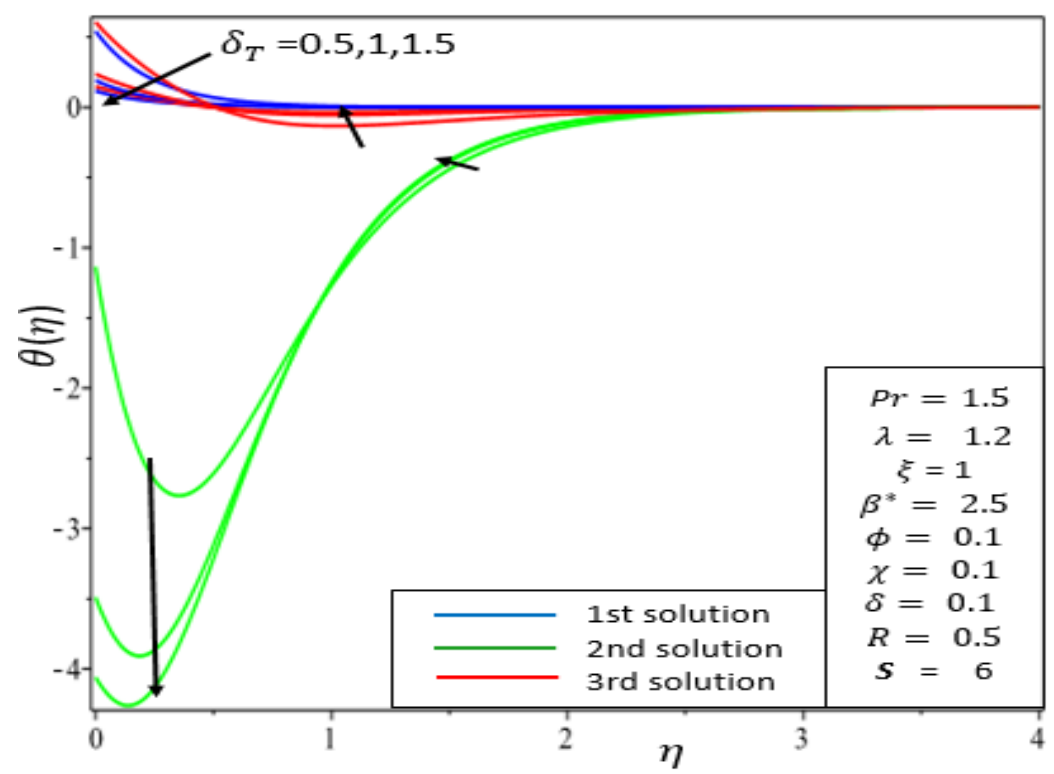

Fig. 15. The temperature profile $\theta(\eta)$ for differet values of $\delta_{T}$

Figure 16 illustrates that an increment in the heat source parameter $(\chi)$, the temperature profile $\theta(\eta)$ and its boundary thickness increase in first solution throughout the flow whereas in second solution opposite to it decrease and in third solution at start it increases but after a while it decreases.

For the stability analysis, collocation method involving three stage Lobatto Illa formula has been used in BVP4C in Matlab software. The obtained smallest eigenvalues are presented in the Table 3, in which it is declared the first solution is the stable and the physically feasible because of the obtained smallest eigenvalues are positive, while second and third solutions are seen unstable because of possessing negative eigenvalues. 


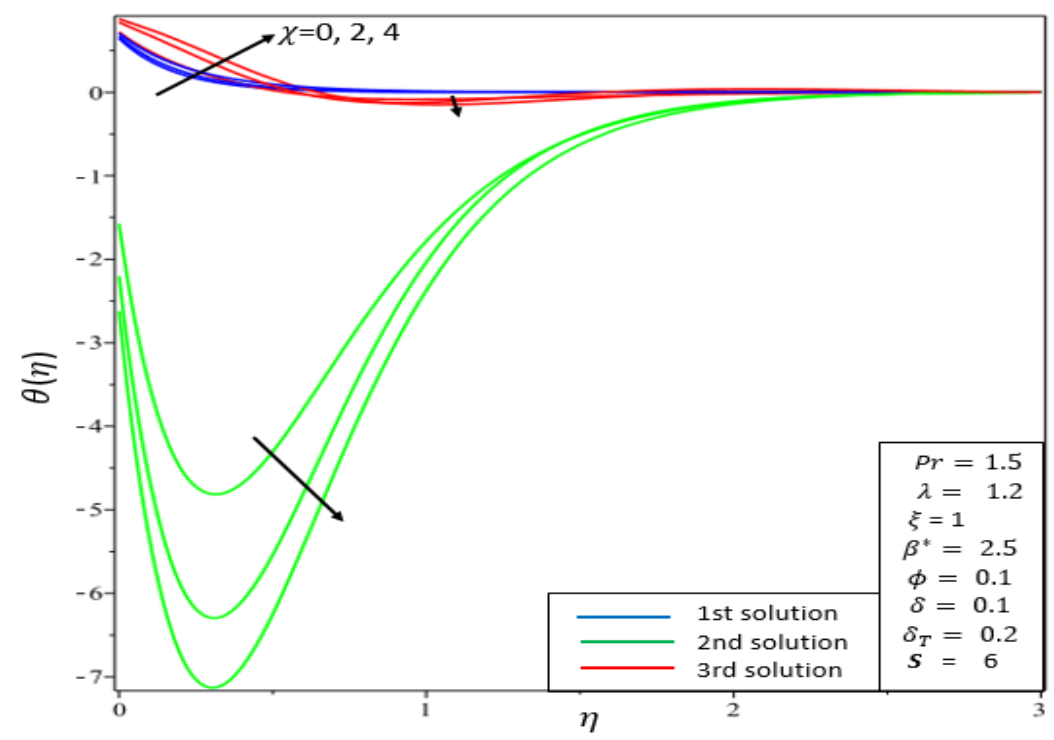

Fig. 16. The temperature profile $\theta(\eta)$ for differet values of $\chi$

Table 3

The smallest eigenvalues for different values of parameters $\beta^{*}, \lambda$ and $S$

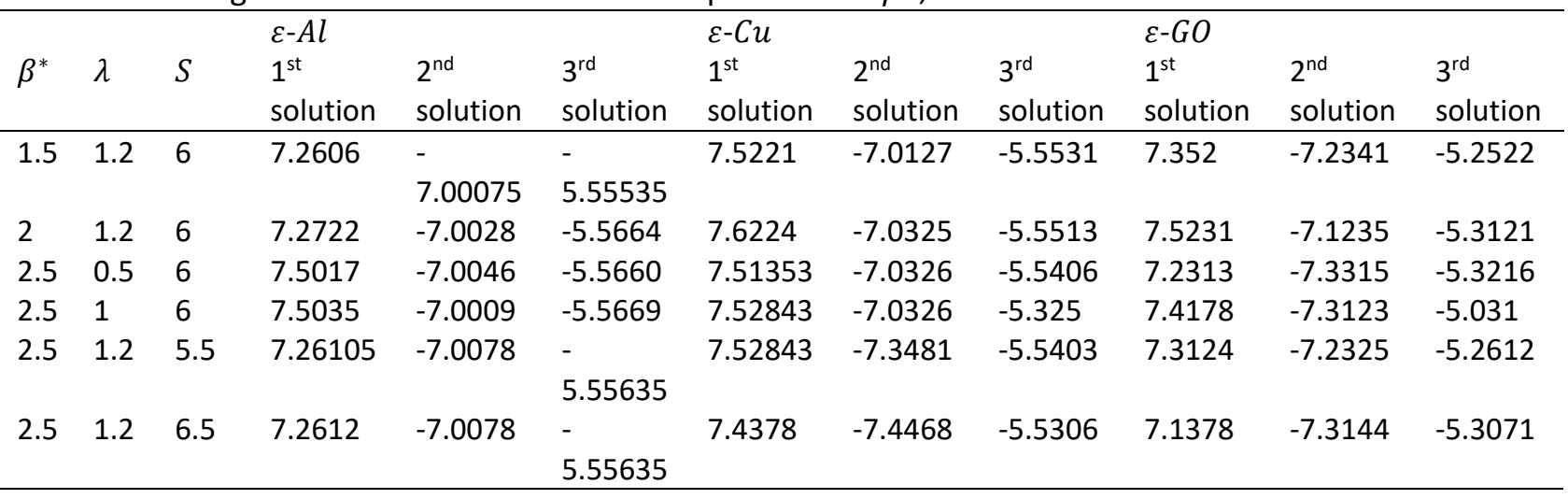

\section{Conclusions}

Numerical study is performed to study the boundary layer flow and the heat transfer of Copper, Aluminum and Graphite Oxide Casson based nanofluid along an exponential vertically stretching/shrinking sheet with heat source/sink, thermal radiation and slip parameters. A singlephase fluid model presented by the Tiwari and Manab [16] is used to modify the present equations. The similarity solutions of the equations are obtained. Then the resulting equations are solved by applying shooting technique in Maple software. Triple solutions are observed for different ranges of the pertinent parameters at high rate of suction. The stability analysis is done and first solution is found as a stable solution. Based on numerical observations, following conclusions can be made.

i. Triple solutions are observed to occur for the certain ranges of suction parameter $S$ and stretching/shrinking parameter $\lambda$. High suction is one of the main reasons behind the occurrence of the triple solutions in present problem.

ii. The suspension of Graphite Oxide nanoparticles in Casson fluid provides more drag force compared to copper and Aluminum nanoparticles.

iii. The copper nanoparticles in Casson fluid provides more rate of the heat transfer enhancement compared to Aluminum and Graphite nanoparticles. 
iv. An increase in velocity slip and Casson parameters decline velocity profiles and their boundary layer thicknesses.

\section{Acknowledgement}

The authors would like to acknowledge Universiti Utara Malaysia for financial support through University Grant (S/O Code: 13873).

\section{References}

[1] Sakiadis, Byron C. "Boundary-layer behavior on continuous solid surfaces: I. Boundary-layer equations for twodimensional and axisymmetric flow." AlChE Journal 7, no. 1 (1961): 26-28.

https://doi.org/10.1002/aic.690070108

[2] Crane, Lawrence J. "Flow past a stretching plate." Zeitschrift für angewandte Mathematik und Physik (ZAMP) 21, no. 4 (1970): 645-647.

https://doi.org/10.1007/BF01587695

[3] Ghosh, Sudipta, and Swati Mukhopadhyay. "Stability analysis for model-based study of nanofluid flow over an exponentially shrinking permeable sheet in presence of slip." Neural Computing and Applications (2019): 1-11. https://doi.org/10.1007/s00521-019-04221-w

[4] Dero, Sumera, Azizah Mohd Rohni, and Azizan Saaban. "The dual solutions and stability analysis of nanofluid flow using tiwari-das modelover a permeable exponentially shrinking surface with partial slip conditions." Journal of Applied Engineering and Science 14, no. 13 (2019): 4569-4582.

https://doi.org/10.36478/jeasci.2019.4569.4582

[5] Dero, Sumera, Azizah Mohd Rohni, and Azizan Saaban. "MHD micropolar nanofluid flow over an exponentially stretching/shrinking surface: Triple solutions." Journal of Advanced Research in Fluid Mechanics and Thermal Sciences 56, no. 2 (2019): 165-174.

[6] Magyari, E., and B. Keller. "Heat and mass transfer in the boundary layers on an exponentially stretching continuous surface." Journal of Physics D: Applied Physics 32, no. 5 (1999): 577. https://doi.org/10.1088/0022-3727/32/5/012

[7] Miklavčič, M., and C. Wang. "Viscous flow due to a shrinking sheet." Quarterly of Applied Mathematics 64, no. 2 (2006): 283-290.

https://doi.org/10.1090/S0033-569X-06-01002-5

[8] Jusoh, Rahimah, Roslinda Nazar, and Ioan Pop. "Magnetohydrodynamic boundary layer flow and heat transfer of nanofluids past a bidirectional exponential permeable stretching/shrinking sheet with viscous dissipation effect." Journal of Heat Transfer 141, no. 1 (2019). https://doi.org/10.1115/1.4041800

[9] Dero, Sumera, Md Jashim Uddin, and Azizah Mohd Rohni. "Stefan blowing and slip effects on unsteady nanofluid transport past a shrinking sheet: Multiple solutions." Heat Transfer-Asian Research 48, no. 6 (2019): 2047-2066. https://doi.org/10.1002/htj.21470

[10] Rahman, M. M., A. V. Roşca, and I. Pop. "Boundary layer flow of a nanofluid past a permeable exponentially shrinking/stretching surface with second order slip using Buongiorno's model." International Journal of Heat and Mass Transfer 77 (2014): 1133-1143. https://doi.org/10.1016/j.ijheatmasstransfer.2014.06.013

[11] Norzawary, Nur Hazirah Adilla, Norfifah Bachok, and Fadzilah Md Ali. "Stagnation Point Flow over a Stretching/shrinking Sheet in a Carbon Nanotubes with Suction/Injection Effects." CFD Letters 12, no. 2 (2020): 106114.

[12] Kwak, Kiyuel, and Chongyoup Kim. "Viscosity and thermal conductivity of copper oxide nanofluid dispersed in ethylene glycol." Korea-Australia Rheology Journal 17, no. 2 (2005): 35-40.

[13] Khanafer, Khalil, Kambiz Vafai, and Marilyn Lightstone. "Buoyancy-driven heat transfer enhancement in a twodimensional enclosure utilizing nanofluids." International Journal of Heat and Mass Transfer 46, no. 19 (2003): 3639-3653.

https://doi.org/10.1016/S0017-9310(03)00156-X

[14] Choi, Stephen US, and Jeffrey A. Eastman. Enhancing thermal conductivity of fluids with nanoparticles. No. ANL/MSD/CP-84938; CONF-951135-29. Argonne National Lab., IL (United States), 1995.

[15] Buongiorno, J. "Convective transport in nanofluids." Journal of Heat Transfer 128, no. 3 (2006): $240-250$. https://doi.org/10.1115/1.2150834 
[16] Tiwari, Raj Kamal, and Manab Kumar Das. "Heat transfer augmentation in a two-sided lid-driven differentially heated square cavity utilizing nanofluids." International Journal of Heat and Mass Transfer 50, no. 9-10 (2007): 2002-2018.

https://doi.org/10.1016/i.ijheatmasstransfer.2006.09.034

[17] Che Sidik, Nor Azwadi, Idris M. Adamu, and Muhammad Mahmud Jamil. "Preparation methods and thermal performance of hybrid nanofluids." Journal of Advanced Research in Applied Mechanics 56, no. 1 (2019): 1-10. https://doi.org/10.37934/aram.66.1.716

[18] Khattak, M. A., A. Mukhtar, and S. Kamran Afaq. "Application of nano-fluids as coolant in heat exchangers: a review." Journal of Advanced Research in Materials Science 66, no. 1 (2020): 8-18. https://doi.org/10.37934/arms.66.1.818

[19] Alkasasbeh, Hamzeh Taha. "Numerical solution of micropolar Casson fluid behaviour on steady MHD natural convective flow about a solid sphere." Journal of Advanced Research in Fluid Mechanics and Thermal Sciences 50, no. 1 (2018): 55-66.

[20] Afikuzzaman, Mohammad, Mohammad Ferdows, Raushan Ara Quadir, and Md. Mahmud Alam. "MHD Viscous Incompressible Casson Fluid Flow with Hall Current." Journal of Advanced Research in Fluid Mechanics and Thermal Sciences, 60, no. 2 (2019): 270-282.

[21] Jasim, Abeer Majeed, and Abdul-Sattar JA Al-Saif. "New Analytical Solution Formula for Heat Transfer of Unsteady Two-Dimensonal Squeezing Flow of a Casson Fluid between Parallel Circular Plates." Journal of Advanced Research in Fluid Mechanics and Thermal Sciences 64, no. 2 (2019): 219-243.

[22] Raza, J., A. M. Rohni, Zurni Omar, and Muhammad Awais. "Rheology of the Cu-H2O nanofluid in porous channel with heat transfer: Multiple solutions." Physica E: Low-dimensional Systems and Nanostructures 86 (2017): 248252.

https://doi.org/10.1016/i.physe.2016.10.038

[23] Rohni, Azizah Mohd, Syakila Ahmad, Ahmad Izani Md Ismail, and Ioan Pop. "Boundary layer flow and heat transfer over an exponentially shrinking vertical sheet with suction." International Journal of Thermal Sciences 64 (2013): 264-272. https://doi.org/10.1016/j.ijthermalsci.2012.08.016

[24] Mohd Rohni, Azizah, Syakila Ahmad, and Ioan Pop. "Boundary layer flow over a moving surface in a nanofluid beneath a uniform free stream." International Journal of Numerical Methods for Heat \& Fluid Flow 21, no. 7 (2011): 828-846. https://doi.org/10.1108/09615531111162819

[25] Merkin, J. H. "On dual solutions occurring in mixed convection in a porous medium." Journal of Engineering Mathematics 20, no. 2 (1986): 171-179. https://doi.org/10.1007/BF00042775

[26] Sharma, Rajesh. "Multiple Solutions of Slip Flow and Heat Transfer over an Exponential Shrinking Sheet with Stability Analysis." International Journal of Theoretical and Applied Mechanics 2 (2017).

[27] Mustafa, M., and Junaid Ahmad Khan. "Model for flow of Casson nanofluid past a non-linearly stretching sheet considering magnetic field effects." AIP Advances 5, no. 7 (2015): 077148.

https://doi.org/10.1063/1.4927449

[28] Meade, Douglas B., Bala S. Haran, and Ralph E. White. "The shooting technique for the solution of two-point boundary value problems." Maple Technical Newsletter 3, no. 1 (1996): 1-8.

[29] Harris, S. D., D. B. Ingham, and I. Pop. "Mixed convection boundary-layer flow near the stagnation point on a vertical surface in a porous medium: Brinkman model with slip." Transport in Porous Media 77, no. 2 (2009): 267-285. https://doi.org/10.1007/s11242-008-9309-6

[30] Jat, R. N., and Gopi Chand. "MHD flow and heat transfer over an exponentially stretching sheet with viscous dissipation and radiation effects." Applied Mathematical Sciences 7, no. 4 (2013): 167-180. https://doi.org/10.12988/ams.2013.13015 